\title{
Mean reversion in a price-earnings ratio and under / overvaluation in the Brazilian stock market*
}

\author{
Daniel Penido de Lima Amorim ${ }^{1}$ \\ (D) https://orcid.org/0000-0002-2844-3079 \\ E-mail: daniel_amorim23@hotmail.com
}

\author{
Marcos Antônio de Camargos ${ }^{1,2}$ \\ (D) https://orcid.org/0000-0002-3456-8249 \\ E-mail: marcosac@face.ufmg.br
}

\begin{abstract}
${ }^{1}$ Federal University of Minas Gerais, Center for Research and Graduate Studies in Business Administration, Belo Horizonte, MG, Brazil
${ }^{2}$ Ibmec University, Belo Horizonte, MG, Brazil
\end{abstract}

Received on 03.19.2020 - Desk accepted on 05.08.2020 - $2^{\text {nd }}$. version approved on 09.01.2020

Editor-in-Chief: Fábio Frezatti

Associate Editor: Fernanda Finotti Cordeiro

\begin{abstract}
The market price-earnings ratios differ from those of each share. Despite allowing for several pertinent analyses, authors have rarely addressed these valuation ratios in the Brazilian context. We can use it to evaluate whether the stock market is overvalued (undervalued). In this article, we analyze the mean reversion in a price-earnings ratio based on Ibovespa and identify periods of overvaluation (undervaluation) in the Brazilian stock market. We considered the period from December 2004 to June 2018. Until then, there are no studies that sought to identify periods of overvaluation (undervaluation) in this market. In the analyses, we used non-linear econometric methods. We analyzed the mean reversion in the price-earnings ratio using a unit root test that incorporates a Fourier function in the deterministic term. We identified the periods of market overvaluation (undervaluation) through the regime probabilities obtained from a Markov Switching model, estimated with the price-earnings ratio. The results evidenced that the price-earnings ratio based on the Ibovespa has a non-linear trend and exhibits mean reversion. Thus, this valuation ratio should provide information on the future stock market returns, mostly when it is very dispersed in relation to historical standards. We identified four periods of market overvaluation interposed with five periods of market undervaluation. Mean reversion in the price-earnings ratio contraposes the Efficient Markets Hypothesis. There are no other applications of unit root tests with a Fourier function in the Brazilian context. Furthermore, adopting a Markov Switching model to identify periods of market overvaluation (undervaluation) consists of a methodological contribution. Investors can take advantage of the identification of these periods to establish investment strategies.
\end{abstract}

Keywords: price-earnings ratio, mean reversion, Markov Switching, overvaluation, behavioral finance.

Correspondence address

Daniel Penido de Lima Amorim

Universidade Federal de Minas Gerais, Centro de Pós-Graduação e Pesquisas em Administração

Avenida Presidente Antônio Carlos, 6627, Prédio FACE, Sala 4012 - CEP 31270-901

Pampulha - Belo Horizonte - MG - Brazil

\footnotetext{
* Daniel Penido de Lima Amorim thanks the Coordination for the Improvement of Higher Education Personnel (CAPES) for the essential financial support to carry out this research. The authors would like to thank Aureliano Angel Bressan, the anonymous referees, and the editor of RC\&F for the comments that contributed to the improvement of this article.
} 


\section{INTRODUCTION}

Fama's studies (1965, 1970, 1991, 1995) widely discussed the idea of stock market efficiency. According to this author, each share price moves over time as a random walk, responding to all new information made available to the market, which would lead to the pricing of this asset according to its intrinsic value (Fama, 1995). Since the consolidation of the finance field until the 1970s, few authors questioned the idea of efficient markets (Shiller, 2003).

However, a seminal article by Shiller (1981) began to question this idea of market efficiency. This author demonstrated that a dividend discount model, used in the stock pricing, was not enough to explain all the United States (US) stock market volatility. Therefore, there would be the possibility of arbitrage, which contradicts the idea that asset prices incorporate all information immediately.

Our article follows the behavioral finance approach defended by Shiller (1981). Shleifer (2000), Shefrin (2002), Barberis and Thaler (2003), Shiller (2003), and Thaler (2005) reviewed this theoretical field. Decades after the mentioned questioning of the efficiency in the stock market, with the rise of his theoretical perspective, Shiller $(2003,2005,2014)$ stated that the US stock market did not behave as preconized by the Efficient Markets Hypothesis. According to Shiller (2005), stock prices could be temporarily distant from their fundamental values due to reflecting investors' psychological aspects.

In this skepticism environment in relation to the Efficient Markets Hypothesis, market valuation ratios appeared. Shiller $(1989,2005)$ provided both a priceearnings $(\mathrm{P} / \mathrm{E})$ ratio calculated by the contemporary ratio between a stock price index and a company earnings index, the $\mathrm{P} / \mathrm{E} 1$, and a $\mathrm{P} / \mathrm{E}$ that has as divisor an average that considers data from the last ten years of the earnings index, the $\mathrm{P} / \mathrm{E} 10$. These $\mathrm{P} / \mathrm{E}$ ratios became more widely disseminated after Campbell and Shiller (1998) and Shiller (2005). Through the P/E10, these authors identified a substantial stock market overvaluation, the "dot-com bubble."

Amorim et al. (2020) proposed an adaptation of Shiller's method $(1989,2005)$ to construct both the P/ $\mathrm{E} 1$ and the P/E10 based on Ibovespa. Until then, in the Brazilian context, no studies are dealing with market $\mathrm{P} / \mathrm{E}$ ratios. Studies in this context addressed only the individual valuation ratios of shares (e.g., Santos \& Montezano, 2011). In contrast, market $\mathrm{P} / \mathrm{E}$ ratios are constructed based on index portfolios broad enough that such valuation ratios be representative of the stock market. The approach by Amorim et al. (2020) overcomes some difficulties in the Brazilian context, such as the stock price indices of the Brazilian stock exchange (Brasil, Bolsa, Balcão - B3) reincorporate dividends, which make them not suitable for calculating $\mathrm{P} / \mathrm{E}$ ratios, as well as the absence of an earnings index.

In the US context, analysts have extensively addressed the market $\mathrm{P} / \mathrm{E}$ ratios when they state that the stock market is overvalued, such as during the "dot-com bubble" (e.g., Shiller, 2005) or more recently in the period before the Subprime Crisis. When this type of valuation ratio is remarkably high, they often use it to support the argument that there is market overvaluation. In contrast, they can assume a market undervaluation when $\mathrm{P} / \mathrm{E}$ ratios are historically low, which happens, notably, in periods of crisis.

Speculative bubbles, economic crises, and other events imply structural breaks in the time series of P/E ratios (Shiller, 2005). These valuation ratios must exhibit mean reversion so that the relationship between the stock prices and the earnings is not continually broken (Campbell \& Shiller, 1998). Testing the mean reversion is equivalent to testing the Efficient Markets Hypothesis because this behavior provides some informational level about the future stock market returns (Moghaddam \& Li, 2017).

Given the existence of a reasonable number of structural breaks in the time series of $\mathrm{P} / \mathrm{E}$ ratios, it is interesting to assess whether they have a non-linear nature and whether, even so, they exhibit mean reversion. Becker et al. (2012) and Moghaddam and Li (2017) evaluated mean reversion in the P/E10 of the US stock market using a non-linear unit root test, which deals with multiple structural breaks fitted through a Fourier function.

Another interesting issue is identifying periods when a stock market is overvalued (undervalued) based on valuation ratios. However, until then, studies dedicated to this are scarce. Taboga (2011) analyzed the probability of the Euro Zone market being undervalued or overvalued through an earnings yield (E/P) based on the MSCI EMU Index. The author adapted E/P by considering a divisor that consisted of the permanent component of aggregate earnings. He extracted this permanent component from the aggregated earnings time series through a Hodrick-Prescott filter. Taboga 
(2011) defined that markets would be overvalued (undervalued) when $\mathrm{E} / \mathrm{P}$ is above (below) the average value that should have according to past information on prices and earnings. Using a Kalman filter, the author estimated the probabilities of E/P being above (below) these levels. Thus, he identified periods of overvaluation (undervaluation) in the European market.

However, Taboga (2011) suggested that future studies could adopt Markov Switching models to identify periods of market overvaluation (undervaluation). The main difference between the Kalman filter used by this author and the Markov Switching models is that this first method is an approach that deals with continuous unobserved states (regimes) while the second method deals with discrete unobserved states (Mergner, 2009). So far, we did not find studies dedicated to identifying the moments of market overvaluation (undervaluation) based on $\mathrm{P} / \mathrm{E}$ ratios, using Markov Switching models.

Following Taboga's (2011) suggestion, in this article, we used a Markov Switching model to identify the periods of overvaluation (undervaluation) in the Brazilian stock market. We assume that the P/E1 based on Ibovespa moves around two different deterministic terms, the one with the highest value associated with the overvaluation regime and the one with the lowest value associated with the undervaluation regime. Using a Markov Switching model, we estimated the probabilities of the P/E1 incorporates each of the deterministic components, indicating when it was in the corresponding regimes at a given time. Based on these regime probabilities, we dated the periods of overvaluation (undervaluation) in the Brazilian stock market.

\section{METHODS}

In this section, we briefly present the construction method of $\mathrm{P} / \mathrm{E}$ ratios based on Ibovespa adapted by Amorim et al. (2020). We also describe the unit root test proposed by Enders and Lee (2012a, 2012b), adopted to analyze the mean reversion in the P/E1. Finally, we describe a Markov Switching model estimated to identify periods of overvaluation (undervaluation) in the Brazilian stock market.

\subsection{Construction of the P/E1}

For the construction of the historical time series of the $\mathrm{P} / \mathrm{E} 1$ ratio, we have used data for all the shares that participated in the Ibovespa portfolio (during the period
In this article, we analyze the mean reversion in the $\mathrm{P} /$ E1 and identify periods of overvaluation (undervaluation) in the Brazilian stock market using this valuation ratio. We considered the period from December 2004 to June 2018. For this proposal, we adopted two non-linear econometric methods. There are no studies in the Brazilian context with the same purpose. We did not use the $\mathrm{P} / \mathrm{E} 10$ provided by Amorim et al. (2020) in the analysis because it did not have a sufficient number of observations in view of its ten-year moving average of the earnings index.

We show that the P/E1 exhibits mean reversion through a unit root test whose model incorporates a Fourier function in the deterministic term. Therefore, this valuation ratio should provide information on the future stock market returns, mostly when it is very dispersed in relation to historical standards. Thus, in theoretical terms, we provide evidence that contradicts the Efficient Markets Hypothesis. There are no other applications of unit root tests with the Fourier function in the Brazilian context.

Furthermore, we used a Markov Switching model to identify periods of market overvaluation (undervaluation). This approach consists of a methodological contribution. Our results indicate four periods of market overvaluation interposed with five periods of market undervaluation. In practical terms, such identification can be useful in investment strategies, in which investors take advantage of the stock market state. This article advances in a theoretical approach of behavioral finance that, unlike the experimental approach, has still been little explored in empirical studies in the Brazilian context (Silva et al., 2019).

from December 2004 to June 2018), namely: (i) closing prices on the last day of the month, adjusted for stock splits and dividends; (ii) weightings corresponding to the percentual participation attributed, in the referred index, to each share on the last day of the month; (iii) quarterly earnings per share. We collected this data in the Comdinheiro financial database (https://www. comdinheiro.com.br).

The $\mathrm{P} / \mathrm{E}$ ratios construction approach, adapted by Amorim et al. (2020), requires a stock price index (constructed so as not to reincorporate dividends) and an earnings per share index. These indexes follow the weighting factors corresponding to the percentage participation of the shares in the Ibovespa portfolio, which 
vary daily, even though the revision of the shares in this portfolio is quarterly.

We have calculated the stock price index, $I_{P}$, according to Equation 1:

$$
I_{P t}=\frac{\sum_{i=1}^{N} P_{i, t} \rho_{i, t}}{\sum_{i=1}^{N} \rho_{i, t}},
$$

where $P$ represents the price of a share $i$ that compose the Ibovespa, and $\rho$ represents the weighting factor corresponding to the percentage of the share $i$ in the mentioned index taken as a reference.

Furthermore, we have calculated the earnings per share index, $I_{E P S}$, according to Equation 2:

$$
I_{E P S t}=\frac{\sum_{i=1}^{N} E P S_{i, t} \rho_{i, t}}{\sum_{i=1}^{N} \rho_{i, t}},
$$

where EPS represents the earning per share referring to a share $i$ that compose the Ibovespa, and $\rho$ represents the weighting factor corresponding to the percentage of this share in the mentioned stock price index taken as a reference. As $I_{E P S}$ is initially a quarterly indicator, since the earnings per share data are published quarterly, following Shiller (2005), we used linear interpolation to elaborate a monthly time series of this index.

Finally, considering $I_{P}$ and $I_{E P S}$ time series adjusted for inflation based on the Broad Consumer Price Index (IPCA), we have calculated the P/E1 based on Ibovespa according to Equation 3:

$$
P / E 1_{t}=\frac{I_{P t}}{I_{E P S t}} .
$$

Amorim et al. (2020) follow Shiller's (1989, 2005) method at this stage of $\mathrm{P} / \mathrm{E} 1$ calculation. These authors offered an extensive discussion about the methodological approach adapted to provide the $\mathrm{P} / \mathrm{E}$ ratios in the Brazilian stock market context.

The monthly time series of the P/E1 refers to the period from December 2004 to June 2018. Amorim et al. (2020) defined the beginning of this series considering that, in the previous periods, many companies whose shares composed the Ibovespa portfolio did not yet publish the quarterly financial statements, which contain the earnings per share data necessary in the $I_{E P S}$ construction. Table 1 exhibits the summary statistics of the P/E1.

Table 1

Summary statistics of the $P / E 1$

\begin{tabular}{lc}
\hline Statistics & P/E1 \\
\hline Mean & 11.39 \\
\hline Maximum & 26.20 \\
\hline Minimum & 2.41 \\
\hline Standard deviation & 5.24 \\
\hline Number of observations & 163 \\
\hline
\end{tabular}

Source: Prepared by the authors.

\subsection{Enders-Lee Unit Root Test}

The time series of the P/E1 has several structural breaks. Given this, in the analysis of the mean reversion in this valuation ratio, we adopted the unit root test proposed by Enders and Lee (2012a, 2012b), which uses a Fourier function as a non-linear approximation of the deterministic term. This test allows for an indeterminate number of structural breaks with unknown nonlinear functional forms fitted using a combination of trigonometric functions. To understand this test, consider a function similar to the Augmented Dickey-Fuller (ADF) test (except for its deterministic term) specified with the $\mathrm{P} / \mathrm{E} 1$, according to Equation 4 :

$$
\Delta P / E 1_{t}=d_{t}+\rho P / E 1_{t-1}+\sum_{i=1}^{p} \delta_{i} \Delta P / E 1_{t-i}+\varepsilon_{t},
$$

where $\varepsilon_{t}$ consists of a stationary disturbance with variance $\sigma_{\varepsilon}^{2}$, and $d_{t}$ consists of the deterministic term as a function of time. As an approximation of the unknown functional form of $d_{t}$ consider the Fourier expansion represented by Equation 5:

$$
d_{t}=c_{0}+c_{1} t+\sum_{k=1}^{n} \alpha_{k} \operatorname{sen}(2 \pi k t / T)+\sum_{k=1}^{n} \beta_{k} \cos (2 \pi k t / T),
$$

where $c_{0}$ consists of an intercept; $c_{1} t$ consists of a trend; $\sin$ represents a sine function; cos represents a cosine function; $n$ represents the number of frequencies in the approximation (with $n \leq T / 2$ ); $k$ represents a particular frequency; and $T$ represents the number of observations. 
We tested the null hypothesis of a unit root in the time series by evaluating whether $\rho=0$, against the alternative hypothesis of $\rho<0$. The critical values for testing this hypothesis depend only on $k$ and $T$. Enders and Lee (2012b) provide these values. In specifying the test model, we must define the frequency $k$ that leads to the best fit. We must also insert lags of the first differenced variable (in this case, $\Delta P / E 1_{t-i}$ ) to remove the autocorrelation. We evaluated the autocorrelation using the conventional Breusch-Godfrey test.

In Equation 5, if $\alpha_{1}=\beta_{1}=\ldots=\alpha_{n}=\beta_{n}=0$, the data generating process is linear. Therefore, conventional unit root tests are appropriate, instead of the test that considers a Fourier expansion. We can assess this constraint through an $\mathrm{F}$ test. However, if there is a break or a non-linear trend, at least one Fourier frequency must be present in the data generating process.

\subsection{Markov Switching Model}

Hamilton $(1989,1990,1994)$ contributed to the dissemination of Markov Switching models in economic literature. In finance, authors used these models to model the returns of stock price indexes (e.g., Balcombe \& Fraser, 2017; Brooks \& Katsaris, 2005; Driffill \& Sola, 1998), to identify speculative bubbles (e.g., Bahrami et al., 2019; Çevik et al., 2011; Chkili \& Nguyen, 2014; Jiang \& Fang, 2015), or to model the stock market volatility (e.g., Dueker, 1997; Li \& Lin, 2003; Ramchand \& Susmel, 1998; Walid et al., 2011; Wang \& Theobald, 2008), among other applications. There are also studies that include Markov Switching models applied in the Brazilian stock market context (Machado et al., 2017; Martin et al., 2004; Mendes et al., 2018).

In this study, we adopted a Markov Switching model, estimated with the P/E1 ratio based on Ibovespa, as a methodological approach for dating periods of market overvaluation (undervaluation). To understand this model, consider that two different deterministic terms of the P/E1 alternate according to an unobservable discrete state variable, $s$, which denotes the overvaluation regime, $s_{1}$, when $s=1$, and the undervaluation regime, $s_{2}$, when $s=$ 2. Markov Switching models suppose specific models for each of the regimes. In the model specified in this study, we considered as independent variables an intercept, $\alpha_{s}$, which depends on the $s$ regime in which the P/E1 can be, and a trend, $\xi t$, which does not depend on $s$, according to Equation 6:

$$
P / E 1_{t}=\left\{\begin{array}{l}
\alpha_{1_{t}}+\xi t+\varepsilon_{t}, \text { when } s=1 \\
\alpha_{2_{t}}+\xi t+\varepsilon_{t}, \text { when } s=2
\end{array},\right.
$$

where the deterministic component represented by $\alpha_{1 t}+\xi t$ differs from the deterministic component represented by $\alpha_{2}+\xi t$. Furthermore, the errors, $\varepsilon$, are normally distributed. This model differs from that adopted by Chauvet (2002), which does not incorporate autoregressive terms, just because it includes a trend term. In the results section, we show how important this trend is for adjusting the regime probabilities.

As Chauvet (2002) discussed, Markov Switching models that incorporate autoregressive terms may fail to date regimes in the presence of sharp structural breaks in the time series. As a solution, the author suggests adopting Markov Switching models specified with no autoregressive term, which are less sensitive to such breaks. Indeed, the time series of a stock market indicator, as the P/E1, has sharper fluctuations than those of the gross domestic product (GDP) that the author uses to date business cycles.

The $\mathrm{P} / \mathrm{E} 1$ is more volatile than the $\mathrm{P} / \mathrm{E} 10$ since it does not present a 10 -year moving average of the earnings indicator as a divisor of the ratio. However, as mentioned, the P/E10 of the Brazilian stock market does not yet have a historical series long enough for the analysis proposed in this study to be feasible using this valuation ratio.

We should emphasize that, in Equation 6, due to $\alpha_{s}$ depends on $s$, this term distinguishes the two deterministic terms and the models referring to each regime. As a result, we can estimate the probabilities that the $\mathrm{P} / \mathrm{E} 1$ is on the overvaluation regime, $s_{1}$, or the undervaluation regime, $s_{2}$.

The assumption of a first-order Markov process requires that the probability of being on one of the regimes in period $t$ depends on the immediately preceding state, in the instant $t-1$, as represented by Equation 7 :

$$
\begin{aligned}
& p_{1 \mid 1}=P\left(s_{t}=1 \mid s_{t-1}=1\right) \\
& p_{1 \mid 2}=P\left(s_{t}=1 \mid s_{t-1}=2\right) \\
& p_{2 \mid 2}=P\left(s_{t}=2 \mid s_{t-1}=2\right) \\
& p_{2 \mid 1}=P\left(s_{t}=2 \mid s_{t-1}=1\right) .
\end{aligned}
$$

For example, $p_{1 \mid 2}$ consists of the probability of transitioning from the overvaluation regime, $s_{1}$, in period $t-1$, to the undervaluation regime, $s_{2}$, in the instant $t$. Typically, the transition probabilities, assumed to be time-invariant, are presented as a transition matrix, according to Equation 8: 


$$
P=\left[\begin{array}{ll}
p_{1 \mid 1} & p_{1 \mid 2} \\
p_{2 \mid 1} & p_{2 \mid 2}
\end{array}\right] .
$$

The Markov Switching model parameterizes the transition probabilities in terms of a multinomial logit. In brief, the filtering procedure obtains the regime probabilities, and the smoothing technique improves such estimates, considering all the information in the sample. In this study, filtering follows Hamilton's (1989) standard approach, and smoothing is according to Kim's (1994) algorithm. Markov Switching models are estimated by Maximum Likelihood.

\section{RESULTS}

In this section, we analyze the mean reversion in the time series of the P/E1 using the Enders and Lee (2012b) unit root test. Furthermore, we identify the periods of overvaluation (undervaluation) in the Brazilian stock market using a Markov Switching model specified with this valuation ratio.

\subsection{Mean Reversion and Non-Linearity}

The unit root test proposed by Enders and Lee (2012a, 2012b) can detect abrupt breaks in level, but their model best fits the data when there are smooth breaks. This behavior seems to be the case of the $\mathrm{P} / \mathrm{E} 1$, as can be seen in Figure 1. Besides this valuation ratio, the figure shows the predicted values of the model estimated in the test.

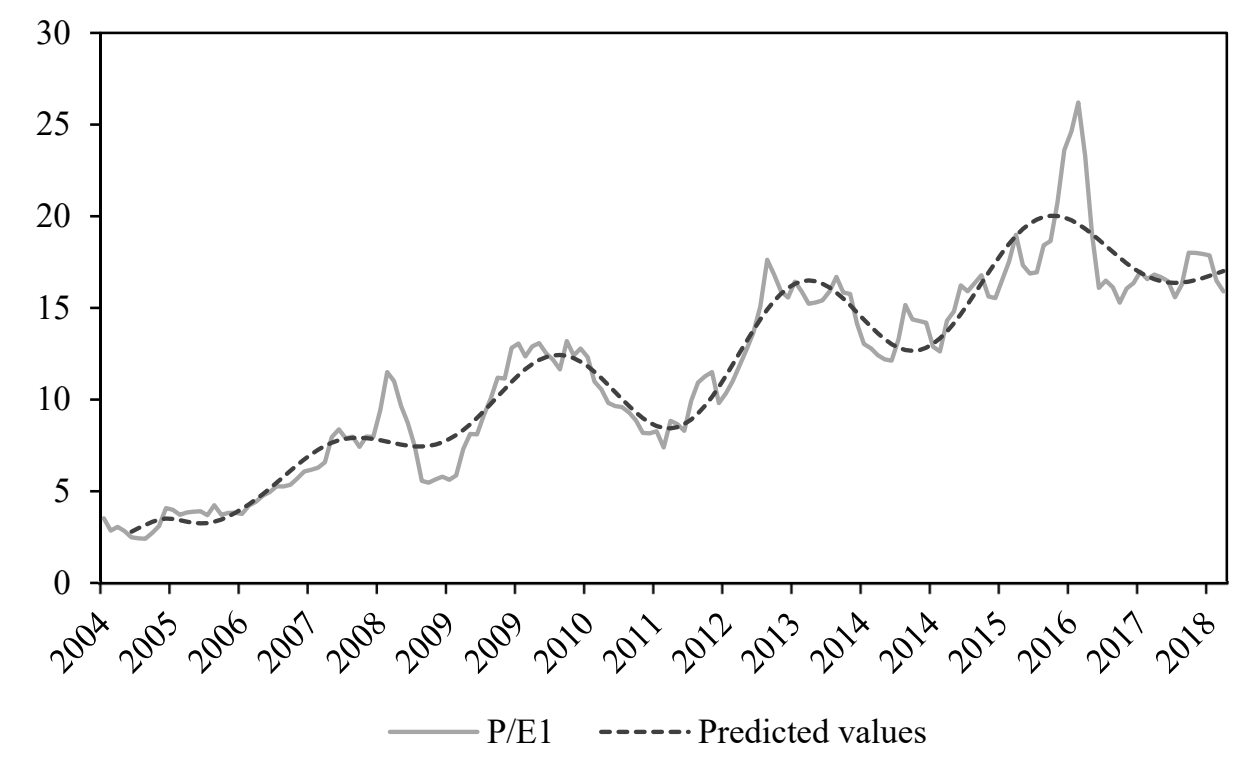

Figure $1 P / E 1$ ratio and values predicted in the Enders-Lee unit root test

Source: Prepared by the authors.

We adjusted the curvature of the predicted values using a Fourier function with five frequencies $(k=5)$, which correspond to the number of cycles in the series. The model estimation with $k=5$ obtained a smaller sum of squares of the residuals and a lower Akaike Information Criterion (AIC) (1973), suggesting a better fit in relation to models estimated with smaller $k$. We consider $k=5$ maximum number of frequencies because Enders and Lee (2012b) did not provide critical values for the unit root test with frequencies higher than this. According to Figure 1, the P/E1 ratio does not appear to have exhibited more than five cycles in the analyzed period.
Dividing the $T$ number of observations of the time series of the $\mathrm{P} / \mathrm{E} 1$ by the $5 k$ frequencies used in the model adjustment, we perceive that the average cycle for this valuation ratio lasts a little less than three years (32.6 months). Observing the stage of the market appreciation cycle can be convenient in establishing investment strategies.

Table 2 exhibits the model estimated in the Enders and Lee (2012b) unit root test applied on the P/E1. This model has a reasonable adjustment, considering its coefficient of determination (R2) and that most of the coefficients are significant. We adopted three lags of the 
first differenced variable $(\Delta \mathrm{P} / \mathrm{E} 1)$ to eliminate the residual autocorrelation. Moreover, we used a heteroskedasticity and autocorrelation consistent (HAC) estimator (Newey \& West, 1987, 1994).

Table 2

Model estimated in the Enders-Lee unit root test

\begin{tabular}{|c|c|c|c|}
\hline Variable & Coefficient & Standard error & t-statistics \\
\hline Intercept & $1.8760^{* * *}$ & 0.3449 & 5.4389 \\
\hline Trend & $0.0383^{* * *}$ & 0.0083 & 4.6148 \\
\hline $\sin (2 \pi 1 t / 163)$ & -0.3273 & 0.2090 & -1.5658 \\
\hline $\cos (2 \pi 1 t / 163)$ & $-0.2018^{* * *}$ & 0.0725 & -2.7824 \\
\hline $\sin (2 \pi 2 t / 163)$ & $-0.3484^{* * *}$ & 0.1259 & -2.7668 \\
\hline $\cos (2 \pi 2 t / 163)$ & $-0.3205^{* * *}$ & 0.1034 & -3.1003 \\
\hline $\sin (2 \pi 3 t / 163)$ & $-0.1923^{* *}$ & 0.0920 & -2.0914 \\
\hline $\cos (2 \pi 3 t / 163)$ & -0.0270 & 0.0941 & -0.2870 \\
\hline $\sin (2 \pi 4 t / 163)$ & 0.0274 & 0.0954 & 0.2876 \\
\hline $\cos (2 \pi 4 t / 163)$ & $-0.5867^{* * *}$ & 0.1400 & -4.1912 \\
\hline $\sin (2 \pi 5 t / 163)$ & $0.3494^{* *}$ & 0.1708 & 2.0455 \\
\hline $\cos (2 \pi 5 t / 163)$ & $0.5087^{* * *}$ & 0.1020 & 4.9849 \\
\hline $\mathrm{P} / \mathrm{E} 1_{\mathrm{t}-1}$ & $-0.4392^{* * *}$ & 0.0674 & -6.5189 \\
\hline$\Delta \mathrm{P} / \mathrm{E} 1_{\mathrm{t}-1}$ & $0.4688^{* * *}$ & 0.0942 & 4.9785 \\
\hline$\Delta \mathrm{P} / \mathrm{E} 1_{\mathrm{t}-2}$ & 0.1434 & 0.0919 & 1.5596 \\
\hline$\Delta \mathrm{P} / \mathrm{E} 1_{\mathrm{t}-3}$ & $0.1672^{* *}$ & 0.0815 & 2.0506 \\
\hline \multicolumn{4}{|c|}{ Diagnostic test statistics } \\
\hline \multicolumn{2}{|l|}{$\mathrm{R}^{2}$} & & 0.3802 \\
\hline \multicolumn{2}{|l|}{ Adjusted $\mathrm{R}^{2}$} & & 0.3152 \\
\hline \multicolumn{2}{|c|}{ Sum of squares of residuals } & & 93.2525 \\
\hline \multicolumn{2}{|c|}{ Akaike Information Criterion } & & 2.5055 \\
\hline \multicolumn{2}{|l|}{ F-statistic } & & 5.8475 \\
\hline \multicolumn{2}{|c|}{ F-statistic - p-value } & & 0.0000 \\
\hline \multicolumn{2}{|c|}{ Breusch-Godfrey autocorrelation LM test $-\chi^{2}(1)$} & & 0.2964 \\
\hline \multicolumn{2}{|c|}{ Breusch-Godfrey autocorrelation LM test - p-value } & & 0.5861 \\
\hline \multicolumn{2}{|c|}{ ARCH LM heteroskedasticity test $-\chi^{2}(1)$} & & 3.1260 \\
\hline \multicolumn{2}{|c|}{ ARCH LM heteroskedasticity test $-p$-value } & & 0.0771 \\
\hline \multicolumn{2}{|c|}{ F linearity test - F-statistic $(10,134)$} & & 5.1820 \\
\hline \multicolumn{2}{|c|}{ F linearity test $-p$-value } & & 0.0000 \\
\hline
\end{tabular}

Note: The dependent variable is $\triangle P / E 1$. We adopted HAC estimators. The estimation method is Ordinary Least Squares (OLS). ***, **, and * denote that the coefficients were significant at the levels of $1 \%, 5 \%$, and $10 \%$ of significance, respectively. The adjusted number of observations is 159. We considered the period from April 2005 to June 2018.

Source: Prepared by the authors.

Table 3 exhibits the Enders and Lee unit root test (2012b). We tested the null hypothesis of a unit root by comparing the $\mathrm{t}$-statistic value (referring to the $\mathrm{P} / \mathrm{E} \mathrm{t}_{\mathrm{t}-1}$ coefficient) with the critical values. We rejected the null hypothesis when the t-statistic is higher than the critical value (both in absolute values) for a given significance level. 
Table 3

Enders-Lee unit root test

\begin{tabular}{lcccc}
\hline Test statistics & Value & Significance & Critical value $(\mathbf{T}=\mathbf{1 0 0})$ & Critical value $(\mathbf{T}=\mathbf{2 0 0})$ \\
\hline $\mathrm{t}$-statistics & -6.52 & $10 \%$ & -3.22 & -3.24 \\
\hline & & $5 \%$ & -3.56 & -3.56 \\
\hline
\end{tabular}

Note: Null hypothesis $\left(H_{0}\right)$ : The variable has a unit root. Enders and Lee $(2012 b)$ provide the critical values referring to $k=5$. Source: Prepared by the authors.

The critical value for a sample of 100 observations at the $1 \%$ significance level is |4.20|, while for 200 observations, this value is $|4.18|$. In this study, we have 163 observations, and the t-statistics is equal to $|6.52|$. Therefore, we can reject the null hypothesis of unit root, regardless of whether we consider the critical value for 100 or 200 observations. Thus, we evidenced that the time series of the P/E1 is trend stationary. This result suggests that this valuation ratio exhibits mean reversion since we consider a trend.

The result for P/E1 behavior in the Brazilian stock market is similar to that found by Becker et al. (2012) and Moghaddam and Li (2017) for P/E10 of the US stock market. These authors also applied a unit root test with Fourier expansion and found that the time series of the P/E ratio is stationary and therefore exhibits mean reversion.

According to Moghaddam and Li (2017), testing whether $\mathrm{P} / \mathrm{E}$ exhibits mean reversion is equivalent to testing the Efficient Markets Hypothesis. The mean reversion behavior, evidenced for the P/E1 through the Enders and Lee (2012b) unit root test, implies a certain level of predictability of the future stock market returns, which contradicts the Efficient Markets Hypothesis. Campbell and Shiller (1998) argue that stock prices should not continually break the relationship with corporate earnings. These authors also affirm that the most relevant changes in $\mathrm{P} / \mathrm{E}$ ratios occur through the stock prices. Thus, especially when the $\mathrm{P} / \mathrm{E} 1$ is remarkably dispersed, it is reasonable to expect prices to vary to bring this valuation ratio back to historical standards. Investors can consider the P/E1 mean reversion in investment strategies.

If the stock market is not efficient, there may be periods of overvaluation or undervaluation. In the next section of this article, we identify such periods.

\subsection{Identifying Periods of Market Overvaluation (Undervaluation)}

Since the time series of the $\mathrm{P} / \mathrm{E} 1$ is stationary and this valuation ratio exhibits a cyclical behavior, there must be periods with higher values and other periods with lower values. In this study, we have associated such periods with two different regimes: an overvaluation regime and an undervaluation regime.

We sought to date such periods by estimating a Markov Switching model. The model estimated in this study allows us to access the probabilities of the P/E1 incorporates its deterministic terms of higher or lesser values at a given time. These probabilities provide evidence that the valuation ratio was on one of the mentioned regimes at that time.

Initially, we also assessed the possibility of three regimes in the Markov Switching model. However, in the estimation that considered the third regime, the model did not even converge, suggesting that the P/E1 should not transit through more than two regimes.

Figure 2 illustrates the time series of the P/E1, the predicted values, and smoothed probabilities obtained using the estimated Markov Switching model. The predicted values correspond to the trajectory over two deterministic terms of the time series of the P/E1. The alternation between these two deterministic terms depends on the intercept value, $\alpha$, which vary according to a discrete unobservable variable, $s$, related to the two different regimes. The smoothed probabilities suggest four periods of market overvaluation and five periods of market undervaluation, between December 2004 and June 2018. 


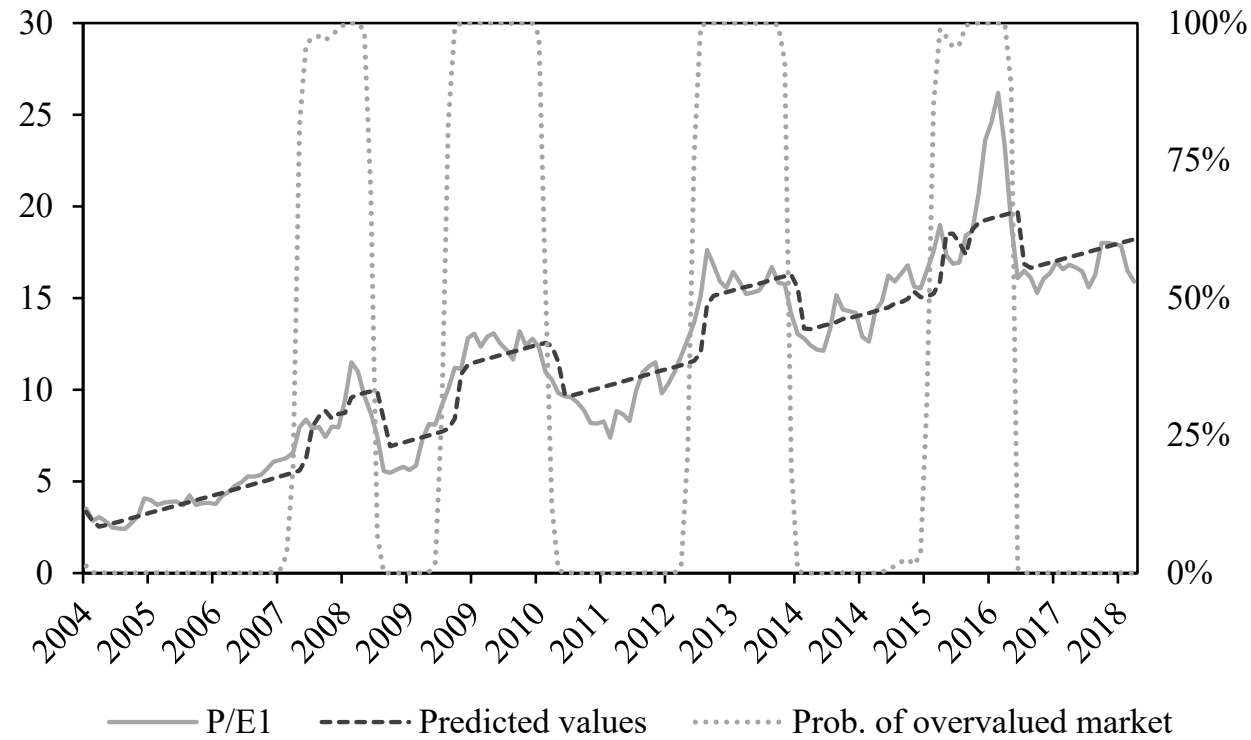

Figure 2 P/E1 ratio, predicted values, and probabilities of the Markov Switching model

Note. The left axis refers to $P / E 1$ values and predicted values, while the right axis refers to the probabilities of the $s=1$ (overvaluation) regime.

Source: Prepared by the authors.

It is interesting to note that the $\mathrm{P} / \mathrm{E} 1$ of the Brazilian stock market is a trend stationary series. Therefore, the identification of periods of overvaluation (undervaluation) must consider a trend and not just the average of the valuation ratio (analysts have typically compared the values of the P/E10 of the US stock market with the historical average). Consider a trend term in the Markov Switching model estimated in this study is equivalent to extracting the trend from the data of the P/E1, according to FrischWaugh Theorem. Thus, the regime probabilities are like those of a stationary series in level. Therefore, higher $\mathrm{P} / \mathrm{E} 1$ values do not necessarily imply an overvaluation regime, as shown in Figure 2.

A possible explanation for the $\mathrm{P} / \mathrm{E} 1$ exhibiting a positive trend is the increase in the volume of investments in the Brazilian stock market. Since the year 2000, the volume traded on this stock market has grown considerably. Saatcioglu and Starks (1998) and Gündüz and Hatemi-J (2005) discuss the positive relationship found in the literature between stock prices and volume and provide evidence for emerging markets. The dissemination of investment culture has also increased in recent decades. According to Shiller
(1984) and Hirshleifer (2020), social dynamics, such as this, influence stock prices.

Table 4 exhibits the results of the estimated Markov Switching model. Regime-dependent intercepts $\alpha_{1}$ and $\alpha_{2}$ are significant. The trend and residual variance $(\sigma)$, regime-invariant parameters, are also significant. The estimated values of the deterministic terms depend on the regime and the instant in time. We can interpret the different intercepts as supposed trend values at the initial point $(t=0)$ for each of the two regimes, and the trend coefficient corresponds to the variations in it at each instant of time. The transition matrix parameters are also significant, suggesting that the model was, in fact, able to identify two different regimes for the P/E1.

Following Engel and Hamilton (1990) and Resende (1999), we tested the null hypothesis that the intercepts, referring to the different regimes, be equal. We make this by applying a Wald test, which imposed a restriction corresponding to the referred equality. This Wald test generated a $\chi^{2}(1)$ statistics with a value of 190.61 and a p-value near zero (0.0000). Hence, we reject the mentioned null hypothesis. This result corroborates the existence of two different regimes in the time series of the P/E1. 
Table 4

Estimated Markov Switching model

\begin{tabular}{|c|c|c|c|}
\hline Variable & Coefficient & Standard error & z-statistics \\
\hline \multicolumn{4}{|l|}{ Regime-dependent intercepts } \\
\hline$\alpha_{1}$ & $5.8950^{* * *}$ & 0.2847 & 20.7088 \\
\hline$\alpha_{2}$ & $2.1680^{* * *}$ & 0.2201 & 9.8480 \\
\hline \multicolumn{4}{|l|}{ Common terms } \\
\hline Trend & $0.0982^{* * *}$ & 0.0028 & 35.5549 \\
\hline $\log (\sigma)$ & $0.2669^{* *}$ & 0.1052 & 2.5375 \\
\hline \multicolumn{4}{|l|}{ Transition matrix parameters } \\
\hline$s_{1}$ & $2525^{* * *}$ & 0.4057 & 6.0452 \\
\hline$s_{2}$ & $-3.2882^{* * *}$ & 0.4068 & -8.0839 \\
\hline \multicolumn{4}{|l|}{ Constant transition probabilities } \\
\hline$p_{1 \mid 1}$ & & & $92.07 \%$ \\
\hline$p_{1 \mid 2}$ & & & $7.93 \%$ \\
\hline$p_{2 \mid 2}$ & & & $96.40 \%$ \\
\hline$p_{2 \mid 1}$ & & & $3.60 \%$ \\
\hline \multicolumn{4}{|l|}{ Constant expected durations } \\
\hline$s_{1}$ & & & 12.62 \\
\hline$s_{2}$ & & & 27.80 \\
\hline \multicolumn{4}{|l|}{ Diagnostic test statistics } \\
\hline Likelihood log & & & -298.7134 \\
\hline Shapiro-Wilk test - z-statistics & & & 1.4811 \\
\hline Shapiro-Wilk test-p-value & & & 0.4768 \\
\hline
\end{tabular}

Note: The dependent variable is P/E1. We did not specify auto-regressive terms and adopted Huber-White estimators, robust to heteroskedasticity. The estimation method is Maximum Likelihood. ***,**, and * denote that the coefficients were significant at the levels of $1 \%, 5 \%$, and $10 \%$ of significance, respectively. The number of observations is 163 . We considered the period from December 2004 to June 2018.

Source: Prepared by the authors.

The transition probabilities are highly dependent on the regime in which the P/E1 was at the immediately previous instant $(t-1)$. When this valuation ratio enters a regime, it tends to remain in that for some time. As exhibited in Table 4, the probability that the P/E1 remains on the overvaluation regime $\left(p_{1 \mid 1}\right)$ is $92.07 \%$, and the probability that the $\mathrm{P} / \mathrm{E} 1$ remains on the undervaluation regime $\left(p_{2 \mid 2}\right)$ is $96.4 \%$. The transition probabilities are inverse to the probabilities that the $\mathrm{P} / \mathrm{E} 1$ remains on the same regimes in which this valuation ratio was at $t-1$. Therefore, the probability of the $\mathrm{P} / \mathrm{E} 1$ transits from the overvaluation regime to the undervaluation regime $\left(p_{1 \mid 2}\right)$ is $7.93 \%$, and the probability of this valuation ratio transits from the undervaluation regime to the overvaluation regime $\left(p_{2 \mid 1}\right)$ is $3.6 \%$.

Furthermore, the overvaluation regime $\left(s_{1}\right)$ has an expected duration shorter than that of the undervaluation regime $\left(s_{2}\right)$. While the $\mathrm{P} / \mathrm{E} 1$ remains for about 12 months on the overvaluation regime, it remains about 28 months on the undervaluation regime (on average). Therefore, periods of market overvaluation are less durable.

Finally, it is worth mentioning that the Shapiro-Wilk test did not reject the null hypothesis that the residuals have a normal distribution. It is also relevant to state that we have adopted Huber-White estimators, which are robust to heteroskedasticity. Naturally, there is a permanence of autocorrelation in a Markov Switching model estimated with only intercept and trend as independent variables. However, the Markov chain correlation must capture a considerable part of the correlation between the residuals.

Autocorrelation can affect the standard errors, therefore, the significance of the coefficients. However, we understand that a time series well fitted using a Fourier function, due to exhibit cycles, should also be well fitted adopting a Markov Switching model, exhibiting two significant intercepts. Furthermore, a time trend term in a model estimated with a dependent variable that is trend stationary should be significant. 
The consideration of autoregressive terms, as in Hamilton's (1989) model, could correct autocorrelation. However, models estimated with these terms were not effective in dating periods of market overvaluation (undervaluation). These models did not obtain significant transition parameters, indicating that they failed to identify two regimes. Autocorrelation does not rule out the effectiveness of the model adopted in this article to date regimes.

As mentioned, the smoothed probabilities obtained from the estimated Markov Switching model allow us to date the periods of market overvaluation (undervaluation). Hamilton (1989) used smoothed probabilities to date business cycles in the US context, Chauvet (2002) used these probabilities to date such cycles in Brazil, while Resende (1999) used them to date mergers and acquisitions waves in the United Kingdom.

In this study, we assumed that when the probabilities of an overvalued market regime were greater than $50 \%$, the market would be overvalued; otherwise, it would be undervalued. Hamilton (1989), Resende (1999), and Chauvet (2002) also dated the regimes in this way. It is worth noting that these probabilities (shown in Figure 2) do not remain at intermediate values, reducing the uncertainty about the stock market regimes. Considering the period from December 2004 to June 2018, Table 5 summarizes the stock market state at different times.

Table 5

Dating of periods of market overvaluation (undervaluation)

\begin{tabular}{cccc}
\hline Periods & Duration & Regime & Market State \\
\hline 2004-12 to 2007-08 & 33 & $s_{2}$ & Undervalued \\
\hline 2007-09 to 2008-08 & 12 & $s_{1}$ & Overvalued \\
\hline 2008-09 to 2009-07 & 11 & $s_{2}$ & Undervalued \\
\hline $2009-08$ to $2010-11$ & 16 & $s_{1}$ & Overvalued \\
\hline $2010-12$ to $2012-09$ & 22 & $s_{2}$ & Undervalued \\
\hline $2012-10$ to $2013-12$ & 15 & $s_{1}$ & Overvalued \\
\hline $2014-01$ to $2015-10$ & 22 & $s_{2}$ & Undervalued \\
\hline $2015-11$ to $2016-11$ & 13 & $s_{1}$ & Overvalued \\
\hline $2016-12$ to $2018-06$ & 19 & $s_{2}$ & Undervalued \\
\hline
\end{tabular}

Note: Duration is given in months.

Source: Prepared by the authors.

As exhibited in Table 5, we identified five periods of undervaluation interposed with four periods of overvaluation in the Brazilian stock market. The longest undervaluation regime occurred from December 2004 to August 2007, while that shortest occurred from September 2008 to June 2009. On the other hand, the longest overvaluation regime occurred from August 2009 to December 2010, while the shortest occurred from September 2007 to August 2008.

Some of these periods coincide with shocks, as the Subprime Crisis, and the impeachment process of Brazil's President, in 2016. This political process motivated high returns of the Ibovespa. By applying a linear unit root test, which endogenously identifies structural breaks in the time series of a variable, Amorim et al. (2020) showed that, in the Brazilian stock market, the time series of the P/E1 has a structural break at the period of the opening of the process that culminated in the mentioned impeachment. According to them, this structural break represents a rupture of stock prices with their fundamentals.

The behavior of Brazilian interest rates should play a relevant role in determining periods of market overvaluation (undervaluation). Amorim and Camargos (2020) analyzed the relationship between the P/E ratios of the Brazilian stock market and the interest rates corresponding to Treasury bond returns. These authors found cointegration and long-run relationships between these variables using models with risk variables regarding the stock market and bond market. The econometric analysis of the determinants of periods of overvaluation (undervaluation) is beyond the scope of this article. 


\section{FINAL REMARKS}

In this study, we evaluated the stationarity of the $\mathrm{P} /$ E1 based on Ibovespa using the Enders and Lee (2012b) unit root test, which models the non-linearity of the time series using a Fourier expansion. This test suggested that the P/E1 has a stationary time series, moving around a non-linear trend over time. Therefore, when the $\mathrm{P} / \mathrm{E} 1$ is remarkably dispersed in relation to its historical behavior, it must exhibit mean reversion sometime later. The most relevant changes in $\mathrm{P} / \mathrm{E}$ ratios occur through the stock prices (Campbell \& Shiller, 1998). Therefore, in such circumstances, the P/E1 based on Ibovespa should provide information about the future stock market returns, which contradicts the Efficient Markets Hypothesis.

Furthermore, through a Markov Switching model estimated using the P/E1, we identified periods in which this valuation ratio incorporates specific deterministic terms. We suppose that these terms are referring to the overvaluation regime and the undervaluation regime. We evidenced four periods of market overvaluation between December 2004 and June 2018. The behavior of the P/E1 corroborates the adoption of investment strategies based on this valuation ratio. The observation of the cycle phase (or the regime), in which this valuation ratio is, may be useful in the formulation of such strategies.

Future studies can investigate the role of some macroeconomic factors in determining the periods of overvaluation (undervaluation) in the Brazilian stock market. To perform this analysis, considering the $\mathrm{P} / \mathrm{E} 1$ as a dependent variable, one can estimate Markov Switching models with transition probabilities that vary with some macroeconomic factors. Particularly in the literature, there is a discussion about the impact of interest rates corresponding to Treasury bond returns on valuation ratios (e.g., Amorim \& Camargos, 2020; Asness, 2003). Therefore, a Markov Switching model in which the transition probabilities depend on the level of interest rates would be pertinent. Moreover, one can use a probit model to test the macroeconomic determinants of the market states. The dependent variable of this model (dummy) should denote the periods of overvaluation (undervaluation).

\section{REFERENCES}

Akaike, H. (1973) Information theory as an extension of the maximum likelihood principle. In B. N. Petrov \& F. Csaki (Eds.), Second International Symposium on Information Theory (pp. 267-281). Budapest: Akademiai Kiado.

Amorim, D. P. L., Camargos, M. A., \& Bressan, A. A. (2020). Mean reversion of the Ibovespa price-earnings ratios. Latin American Business Review, 21(4), 1-26.

Amorim, D. P. L., \& Camargos, M. A. (2020). Relações entre índices preço-lucro e retornos dos títulos públicos. Revista Brasileira de Finanças, 18(3), 27-51.

Asness, C. S. (2003). Fight the Fed Model. The Journal of Portfolio Management, 30(1), 11-24.

Bahrami, A., Shamsuddin, A., \& Uylangco, K. (2019). Are advanced emerging market stock returns predictable? A regime-switching forecast combination approach. PacificBasin Finance Journal, 55, 142-160.

Balcombe, K., \& Fraser, I. (2017). Do bubbles have an explosive signature in Markov switching models? Economic Modelling, 66, 81-100.

Barberis, N., \& Thaler, R. (2003). A survey of Behavioral Finance. In G. M. Constantinides, M. Harris, \& R. M. Stulz (Eds.), Handbook of the Economics of Finance (vol. 1, Part 2, p. 10531128). Amsterdam: Elsevier.

Becker, R., Lee, J., \& Gup, B. E. (2012). An empirical analysis of mean reversion of the S\&P 500's P/E ratios. Journal of Economics and Finance, 36(3), 675-690.
Brooks, C., \& Katsaris, A. (2005). A three-regime model of speculative behaviour: Modelling the evolution of the S\&P 500 Composite Index. The Economic Journal, 115(505), 767797.

Campbell, J. Y., \& Shiller, R. J. (1998). Valuation ratios and the long-run stock market outlook. The Journal of Portfolio Management, 24(2), 11-26.

Çevik, E. İ., Korkmaz, T., \& Atukeren, E. (2011). Business confidence and stock returns in the USA: A time-varying Markov regime-switching model. Applied Financial Economics, 22(4), 299-312.

Chauvet, M. (2002). The Brazilian business and growth cycles. Revista Brasileira de Economia, 56(1), 75-106.

Chkili, W., \& Nguyen, D. K. (2014). Exchange rate movements and stock market returns in a regime-switching environment: Evidence for BRICS countries. Research in International Business and Finance, 31, 46-56.

Driffill, J., \& Sola, M. (1998). Intrinsic bubbles and regimeswitching. Journal of Monetary Economics, 42(2), 357-373.

Dueker, M. J. (1997). Markov switching in GARCH processes and mean-reverting stock-market volatility. Journal of Business \& Economic Statistics, 15(1), 26-34.

Enders, W., \& Lee, J. (2012a). A unit root test using a Fourier series to approximate smooth breaks. Oxford Bulletin of Economics and Statistics, 74(4), 574-599. 
Enders, W., \& Lee, J. (2012b). The flexible Fourier form and Dickey-Fuller type unit root tests. Economics Letters, 117(1), 196-199.

Engel, C., \& Hamilton, J. (1990). Long swings in the Dollar: Are they in the data and do markets know it? American Economic Review, 80(4), 689-713.

Fama, E. F. (1965). The behavior of stock-market prices. The Journal of Business, 38(10), 34-105.

Fama, E. F. (1970). Efficient capital markets: A review of theory and empirical work. The Journal of Finance, 25(2), 28-30.

Fama, E. F. (1991). Efficient capital markets: II. The Journal of Finance, 46(5), 1575-1617.

Fama, E. F. (1995). Random walks in stock market prices. Financial Analysts Journal, 51(1), 75-80.

Gündüz, L., \& Hatemi-J, A. (2005). Stock price and volume relation in emerging markets. Emerging Markets Finance and Trade, 41(1), 29-44.

Hamilton, J. D. (1989). A new approach to the economic analysis of nonstationary time series and the business cycle. Econometrica, 57(2), 357-384.

Hamilton, J. D. (1990). Analysis of time series subject to changes in regime. Journal of Econometrics, 45(1-2), 39-70.

Hamilton, J. D. (1994). Modeling time series with changes in regime. In J. D. Hamilton. Time series analysis (p.677-703). Princeton, NJ: Princeton University Press.

Hirshleifer, D. (2020). Presidential address: Social transmission bias in Economics and Finance. The Journal of Finance, 75(4), 1779-1831.

Jiang, Y., \& Fang, X. (2015). Bull, bear or any other states in US stock market? Economic Modelling, 44, 54-58.

Kim, C.-J. (1994). Dynamic linear models with Markov-switching Journal of Econometrics, 60(1-2), 1-22.

Li, M.-Y. L., \& Lin, H.-W. W. (2003). Examining the volatility of Taiwan Stock Index returns via a three-volatility-regime Markov-switching ARCH model. Review of Quantitative Finance and Accounting, 21(2), 123-139.

Machado, M. R. R., Gartner, I. R., \& Machado, L. S. (2017). Relação entre Ibovespa e variáveis macroeconômicas: Evidências a partir de um modelo Markov-switching. Revista Brasileira de Finanças, 15(3), 435-468.

Martin, D. M. L., Kayo, E. K., Kimura, H., \& Nakamura, W. T. (2004). Identificando bolhas especulativas racionais no IBOVESPA (pós-Plano Real), a partir de regimes markovianos de conversão. EconomiA, 5(3), 219-252.

Mendes, F. H. P. S., Moura, G. V., \& Caldeira, J. F. (2018). Evidence of bull and bear markets in the Bovespa index: An application of Markovian regime-switching models with duration dependence. Brazilian Review of Econometrics, 38(1), 39-74.

Mergner, S. (2009). Applications of state space models in Finance: An empirical analysis of the time-varying relationship between macroeconomics, fundamentals and Pan-European industry portfolios. Göttingen, NI: Universitätsverlag Göttingen.

Moghaddam, M., \& Li, Y. (2017). Searching for the P/E mean reversion affinity - an application of the flexible Fourier approximation. The Journal of Business Inquiry, 16(2), 102111.

Newey, W. K., \& West, K. D. (1987). A simple, positive semidefinite, heteroskedasticity and autocorrelation consistent covariance matrix. Econometrica, 55(3), 703-708.

Newey, W. K., \& West, K. D. (1994). Automatic lag selection in covariance matrix estimation. The Review of Economic Studies, 61(4), 631-653.

Ramchand, L., \& Susmel, R. (1998). Volatility and cross correlation across major stock markets. Journal of Empirical Finance, 5(4), 397-416.

Resende, M. (1999). Wave behaviour of mergers and acquisitions in the UK: A sectoral study. Oxford Bulletin of Economics and Statistics, 61(1), 85-94.

Saatcioglu, K., \& Starks, L. T. (1998). The stock price-volume relationship in emerging stock markets: The case of Latin America. International Journal of Forecasting, 14(2), 215-225.

Santos, L., \& Montezano, R. (2011). Ações de valor e de crescimento no Brasil: Riscos e retornos de carteiras uni e bidimensionais em diferentes estados da economia. Revista Contabilidade \& Finanças, 22(56), 189-202.

Shefrin, H. (2002). Beyond greed and fear: Understanding behavioral finance and the psychology of investing. Oxford: Oxford University Press.

Shiller, R. J. (1981). Do stock prices move too much to be justified by subsequent changes in dividends? American Economic Review, 71(3), 421-436.

Shiller, R. J. (2003). From efficient markets theory to behavioral finance. Journal of Economic Perspectives, 17(1), 83-104.

Shiller, R. J. (2005). Irrational exuberance (2nd ed.). Princeton, NJ: Princeton University Press.

Shiller, R. J. (2014). The bond market in historical perspective. In R. J. Shiller. Irrational exuberance (3rd ed., p. 11-17). Princeton: Princeton University Press.

Shiller, R. J. (1989). Market volatility. New York, NY: MIT Press.

Shiller, R. J. (1984). Stock prices and social dynamics. Brookings Papers on Economic Activity, 2, 457-510.

Shleifer, A. (2000). Inefficient markets: An introduction to Behavioral Finance. Oxford: Oxford University Press.

Silva, P. V. J. G., Santos, J. B., \& Pereira, G. P. (2019). Behavioral Finance in Brazil: A bibliometric study from 2007 to 2017. Latin American Business Review, 20(1), 61-82.

Taboga, M. (2011). Under-/over-valuation of the stock market and cyclically adjusted earnings. International Finance, 14(1), 135-164.

Thaler, R. (2005). Advances in Behavioral Finance. Princeton, NJ: Princeton University Press.

Walid, C., Chaker, A., Masood, O., \& Fry, J. (2011). Stock market volatility and exchange rates in emerging countries: A Markov-state switching approach. Emerging Markets Review, 12(3), 272-292.

Wang, P., Theobald, M. (2008). Regime-switching volatility of six East Asian emerging markets. Research in International Business and Finance, 22(3), 267-283. 